Original Research Paper

\title{
Groundwater Quality Assessment of Three Zonal Regions in the Sunyani Municipality
}

\author{
${ }^{1}$ Kwabena Antwi Kusi, ${ }^{1}$ Samuel Wiafe and ${ }^{2}$ Patrick Akaribila Nsonini \\ ${ }^{1}$ Department of Civil Engineering, Sunyani Technical University, Ghana \\ ${ }^{2}$ Ghana Water Company Ltd, Sunyani, Ghana
}

Article history

Received: 30-04-2018

Revised: 05-07-2018

Accepted: 13-02-2019

Corresponding Author:

Kwabena Antwi Kusi

Department of Civil

Engineering, Sunyani Technical

University, Ghana

Tell: +233209 122440

Email: kwaantwi@yahoo.com

\begin{abstract}
This project aimed at assessing the variation of ground water quality (physical, chemical and bacteriological parameters) in relation to the WHO standards from fifteen (15) randomly selected ground water sources in three (3) zones namely Abesim, Baakoniaba/Berlin-Top and New-Dormaa in the Sunyani Municipality. Groundwater samples were collected from five sampling points in each zone to determine the quality of the water and the differences in water quality. The selection was mainly from ground water source that has high number of consumers. The study revealed that water sampled from the wells were slightly acidic. Also higher values for Total coliform test were recorded, which is an indication that water from these wells should be well treated before consumption. The research recommends that further analysis should be carried out zones and awareness raised to the low $\mathrm{pH}$ content of groundwater resources in the municipality since the use of groundwater is on the rise.
\end{abstract}

Keywords: Water Quality, Groundwater, Zonal Regions, Physical Parameters

\section{Introduction}

Accessibility and availability of safe drinking water is key to sustainable development. Safe drinking water is essential to life and must be made available to consumers (WHO, 2006; Utsumi and Tsuchiya, 2010; Ackah et al., 2012; Rao et al., 2016). The main sources of water supply to urban areas of Ghana are conventional treatment plants where surface water is taken from rivers (Osumanu et al., 2010; Asiedu, 2012). Generally, ground water sources are limited to only a few areas in the forest zone (Osumanu et al., 2010; Asiedu, 2012). Historically, major feature of these treatment plants has been their inability to produce enough water to meet growing urban demand (Osumanu et al., 2010; Asiedu, 2012). The supply of piped water does not meet the demand of most communities in Ghana (Anthony and Sylvester, 2013; Ackah et al., 2012). As a result of this, some urban residents have turned to groundwater as an alternative source of their water needs. In Ghana, about $45 \%$ of the total drinking water is produced from groundwater (Buamah et al., 2008). The country has $87.2 \%$ of its population having access to safe drinking water a considerable advance on the MDG target of $77 \%$, reflecting a significant national investment in the provision of safe water supplies (www.gh.one.un.org). However, Xu and Usher (2006) pointed out that most ground water sources are polluted and their use has led to increased health problems cited by Obeng (2015). They further stated that sources of groundwater pollution are numerous including uncontrolled expansion of human settlement, high levels of effluent and sewage leakage, mining operations and indiscriminate waste disposal affects ground water quality (Obeng, 2015). The aim of this study was to determine the variation of ground water quality in three zones within the Sunyani municipality namely, Abesim, Baakoniaba/Berlin Top and New Dormaa. This was achieved by mapping out the wells within the three selected zones, determining the variation of ground water quality and to determine the difference in water quality between the three zones and ascertaining the causes of those differences.

\section{Materials and Methods}

Study Area

The study was undertaken in the Sunyani Municipality of Ghana. Sunyani Municipality is the 
capital of the Brong- Ahafo Region of Ghana. It has a total land area of $829.3 \mathrm{~km}^{2}$ (approx. 320.2 square miles) and lies between latitude $7^{0} 20^{\prime} \mathrm{N}$ and $7^{0} 05^{\prime} \mathrm{N}$ and longitude $2^{0} 30^{\prime} \mathrm{W}$ and $2^{0} 10^{\prime} \mathrm{W}$ (Amaniampong, 2015). The municipality shares boundaries with four districts namely; Sunyani West District, Dormaa District, Asutifi District and Tano North District (Amaniampong, 2015).

\section{Climate and Population}

The average monthly temperature of the Municipality varies between $23^{\circ} \mathrm{C}$ and $33^{\circ} \mathrm{C}$, in which the lowest temperature is recorded in August and the highest in March and April. Sunyani Municipality has two rainfall seasons, major and minor. It has high relative humidity of $75-80 \%$ during the rainy season and $70-80 \%$ in the dry season of the year. According to Ghana Statistical Service (GSS), 2000, the population of the municipality in the year 2000 and 2010 were 101,145 and 123,224 respectively, given a population rise of 22,079 . The Municipality has a population density of 122 persons per square kilometer. From the survey conducted by (SMA, 2010 ; 2014) the highly populated areas are Zongo, New Dormaa and Area 2 with an average of $18 \%$ in a household. Abesim, with medium population density has a mean of $13 \%$ in a household and Baakoniaba and Berlin-Top with the low population of $8 \%$ per household. There are 13,226 households in the Municipality. According to SMA (2018) Sunyani Municipal has an average household population of Four (4) persons. Major occupation of the indigenes is farming. The major type of farming activities of the people of Sunyani includes crop, tree, livestock fishing and rearing of farm animal. Hand dug Wells and mechanized boreholes still remain the source of drinking water for most people in Sunyani municipality. Others also use streams, as well as pipe-borne water for their household chores. The Sunyani Municipality has about 4,497 boreholes, 2,513 protected wells as well us over 320 unprotected wells. (GSS, 2000) cited Danquah and Agyei-Ohemeng (2015).

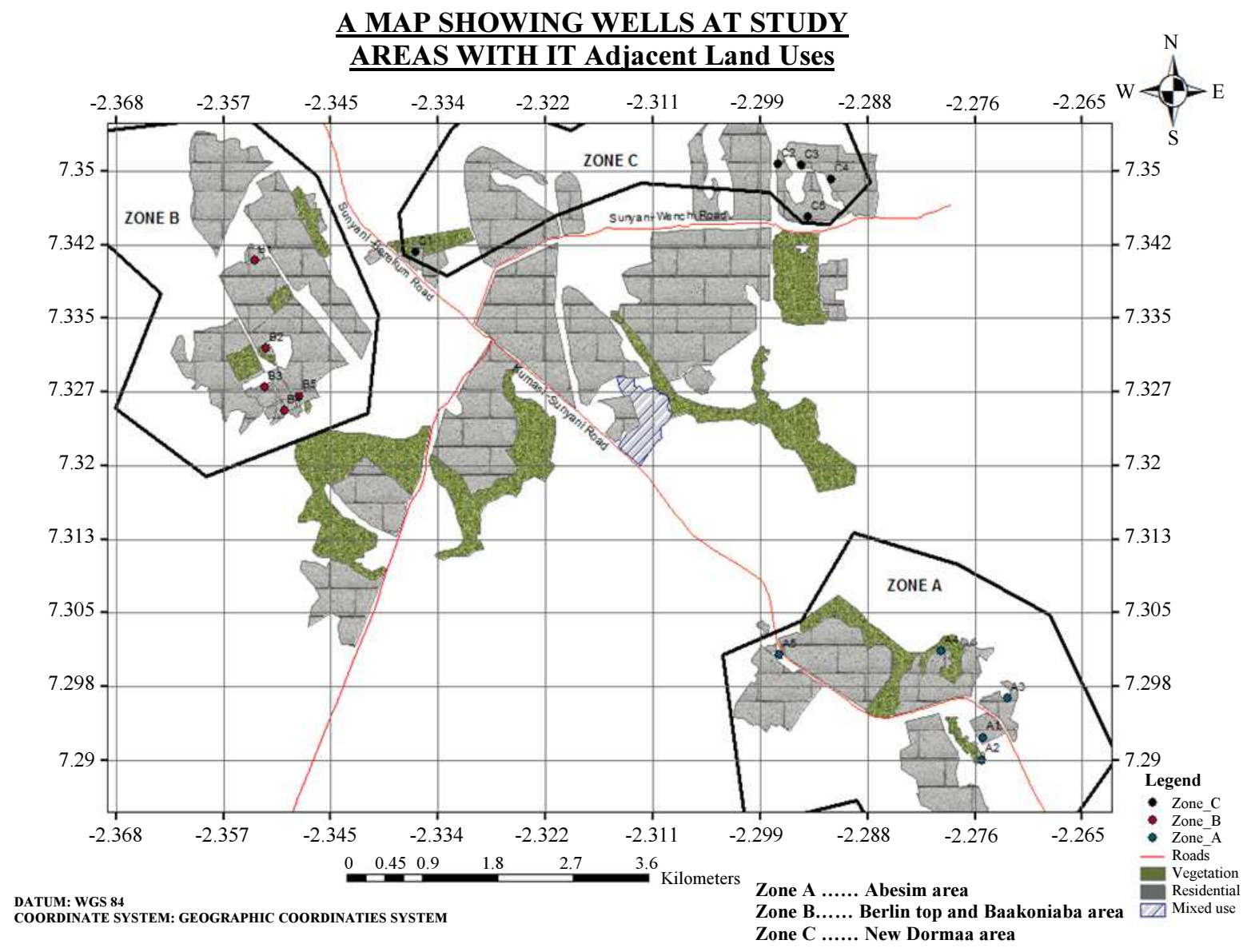

Fig. 1: Map showing wells at the zoned areas with adjacent land uses 


\section{Data Collection/Sampling}

Ground water samples (boreholes and wells) were the main experimental resources. Composite sampling was the methods used in taking samples from the wells. A hand held Garmin 62SC Global Positioning System (GPS) was used for taking coordinates for each sampled wells. Using World Geodetic System (WGS) 84, samples for each of the wells were taken with all the coordinated points converted into shape files, using the geographic coordinates system. The sampled wells collected were zoned into three (3) within the municipality namely, Abesim (Zone A), New- Dormaa (Zone B) and Baakuniba/Berline-Top (Zone C). These zones are uniformly distributed within the municipality (Fig. 1). Ground water sources with high patronage were selected. The samples were labeled as A1-A5, B1-B5 and $\mathrm{C} 1-\mathrm{C} 5$ forground water sources in Abesim, Baakoniba/Berline Top and New-Dormaa respectively. Triplicate sampling were conducted for each of the sampled wells collected. For the purposes of quality control, each of the sample were analysed by acidifying each sample with $\mathrm{HNO}_{3} 1 \% \mathrm{v} / \mathrm{v}$ as according to the Pote et al. (2009). After which, it was then kept at $4{ }^{\circ} \mathrm{C}$ in an ice chest for relatively constant temperature. Sample collected for analysis were clean, a 1.5 litre plastic container with a screw cap thoroughly washed with detergent soaked with acid and rinsed with distilled water. The container was rinsed many times at least three with the water sample at the point of collection. Sample containers were labelled and tightly covered to avoid spillage and any possible contamination during transportation to the Physicochemical and Bacteriological laboratory of the Ghana Water Company Limited, Sunyani, Brong-Ahafo region. The World Health Organisation (WHO) Standard was used to determine the physicochemical properties of the water samples. The following were the parameters determined; Temperature, $\mathrm{pH}$, Turbidity, Total alkalinity, Conductivity, Total hardness, Total Dissolved Solids (TDS), Nitrate, Presence of minerals (such as Fluoride and calcium). It was achieved by the Ethylene-Diamine-Tetra-Acetic acid (EDTA) Titration method. The Hanna Microprocessor $\mathrm{pH}$ meter was used in checking the $\mathrm{pH}$ carried out in-situ at sites of sample collection standardized with buffer solution of $\mathrm{pH}$ ranging from 4 to 9 . Temperature measurement was carried out in-situ on site where samples were collected using a Mobile thermometer, achieved by dipping the thermometer into the sample and recording the stable reading. A conductivity meter was used to determine the electrical of conductivity of the sampled water by probe was dipped into the container of the samples until a stable reading was obtained and recorded. In determining the sampled water's Alkalinity $50 \mathrm{~mL}$ of the sample was pipette into a clean conical flask (250
$\mathrm{mL}$ ). The solution titrated against a standard $0.01 \mathrm{M}$ Hydrogen Chloride $(\mathrm{HCl})$ Solution to a pink end-point by which Two drops of methyl red indicator were added to the solution (APHA, 1992). A standardized Hanna H198703 Turbidimeter was employed in the test for turbidity. The samples were the poured into the measuring bottle and the surface or the bottle was wiped with silicon oil which was then inserted into the turbidimeter and the reading obtained. The Gravimetric Method was used to determine the Total Dissolved Solids (TDS). Portions of the water were filtered out. 10 $\mathrm{mL}$ of the filtrate was then measured into a pre-weighed evaporating dish for drying. It was dried in an oven at a temperature of $103-105^{\circ} \mathrm{C}$ within a period of two and half hours. The dish and its content was transferred into a desiccator and allowed to cool at room temperature and then weighed. The dissolve solids were represented by the difference in the weight of the evaporating dish. 5 drops of Phenolphthalein indicator solution was added to a $50 \mathrm{~mL}$ of the sample to undertake a chlorine ion test and neutralized to the colorless side of phenolphthalein with $0.1 \mathrm{~N}$ sulphuric acid. Addition $1 \mathrm{~mL}$ of potassium chromate indicator solution was done before titration with standard Silver nitrate solution to a pinkish-yellow endpoint. A reagent blank titration was carried out in parallel to the sample titration. The Bacteriological analyses were carried out using MacConkey Broth and Harloquin Machine for presumptive and confirmatory tests respectively. This was done to confirm the existence of $E$. coli but was not to determine the number of its counts per sample. Ten milliliters $(10 \mathrm{~mL})$ of each of the samples were measured with a sterile pipette and mixed homogeneously with $10 \mathrm{ml}$ of a sterile MacConkey broth in five McCartney bottles with inverted Durham tube inside. The McConkey bottles and their contents were incubated at $37^{\circ} \mathrm{C}$ for $24 \mathrm{~h}$. Samples which tested positive by a change of colour of the contents (from wine to yellow) and a presence of trapped gas in the inverted Durham tubes, shows presents of bacteria in the sampling.

\section{Results}

There were variations in the values of $\mathrm{pH}$ recorded from the three zones. The $\mathrm{pH}$ for Zone A was $6.27 \pm 0.31$ which falls below the WHO standard. However, the $\mathrm{pH}$ for Zones $\mathrm{B}$ and $\mathrm{C}$ were all within the WHO standard. The lower levels of $\mathrm{pH}$ in Zone A make it acidic. Generally, water with a $\mathrm{pH}<6.5$ could be acidic, soft and corrosive. Acidic water could contain metal ions such as iron, manganese, copper, lead and zinc. Acidic water contains elevated levels of toxic metals. Acidic water can cause premature damage to metal piping and have associated aesthetic problems such as a metallic or sour taste. It can also stain laundry and cause "blue-green" color staining on 
sinks and drains. More importantly, there are health risks associated with these toxins. The levels of $\mathrm{pH}$ within the enclave of Zone A must regularly checked and controlled before consumption. Groundwater mean temperature values in Zones $\mathrm{A}, \mathrm{B}$ and $\mathrm{C}$ were $28.28 \pm 69.24,28.78 \pm 0.51$ and $28.34 \pm 0.78$ respectively. These suggest that the groundwater temperatures are generally ambient and good for consumers who prefer cool to warm water and for the specific reason of water quality; since, high temperature negatively impact water quality by enhancing the growth of micro-organisms which may increase taste, odour, colour and corrosion problems (UNICEF, 2008). Therefore, it is important that groundwater temperature is not too high in order not to have microbial proliferation. Temperature affects biological, chemical and physical activities in the water (Yilmaz and Koc, 2014). Besides, increase in temperature of water decreases solubility of gases such as $\mathrm{O}_{2}, \mathrm{CO}_{2}, \mathrm{~N}_{2}$ and $\mathrm{CH}_{4}$ (Yilmaz and Koc, 2014). The alkalinity levels in the water samples of Zones $\mathrm{B}$ and $\mathrm{C}$ are relatively high as compared to that of Zone A. these high values tends to make the water more alkaline especially that of Zone B. Alkalinity is a measure of the capacity of the water to resist a change in $\mathrm{pH}$ that would tend to make the water more acidic. The measurement of alkalinity and $\mathrm{pH}$ is needed to determine the corrosiveness of the water. The high levels of alkalinity in Zones $\mathrm{B}$ and $\mathrm{C}$ will resist the tendency of the water from becoming more acidic which may result in the water becoming more corrosive. Thus, the high levels of alkalinity in these two Zones will serve as a means of controlling the $\mathrm{pH}$ levels in the water. The levels of fluoride, Total Hardness, Electrical Conductivity, Turbidity, Colour, Chloride and Total Dissolved Solids were generally within the WHO recommended standards. For the microbiological analysis of the sampled wells, all of them were free from faecal coliform and $E$. coli contamination. However, 9 out of the 15 sampled well waters (representing 60\%) across the zones did have traces of Total Coliform in them. Interestingly, Zone A and Zone $\mathrm{C}$ recorded 4 out of their 5 wells (representing $80 \%$ ) sampled being contaminated whereas, Zone B had 1 out of the $5(20 \%)$ wells being contaminated.

\section{Discussion}

The mean temperature values of the sampled wells were generally low. Cool waters are generally more potable for drinking purposes because high water temperature enhances the growth of micro-organisms hence, taste, odour, colour and corrosion problem may increase (Okoye and Okoye, 2008). Metal corrosion problem are also associated with high temperature especially when the $\mathrm{pH}$ of the water happens to be more acidic. The observed $\mathrm{pH}$ values were generally acidic. The acidic increases in the water samples increased the capacity of the water to attack geological materials and leach toxic trace metals into the water. Electrical Conductivity (EC) is an indicator of water quality and soil salinity, hence the relatively high values observed in some water samples showed high salinity. This suggests that, the groundwater might not be very suitable for domestic and agricultural use. All Total Dissolve Solid (TDS) values were below the optimum $1000 \mathrm{mg} \mathrm{L}^{-1}$ as set by WHO for potable water. The presence of these Total Dissolved Solids (TDS) in the water samples as observed in Table 1 indicated the presence of solid materials or solutes in water. It was observed that the EC of samples increased with increasing TDS results. The alkalinity values of all the sampled waters were below the stipulated limit 100 $\mathrm{mg} \mathrm{L}^{-1}$ by WHO. They ranged from 25 to $300 \mathrm{mg} \mathrm{L}^{-1}$.

Table 1: Physical and Bacteriology parameters of the sampled wells

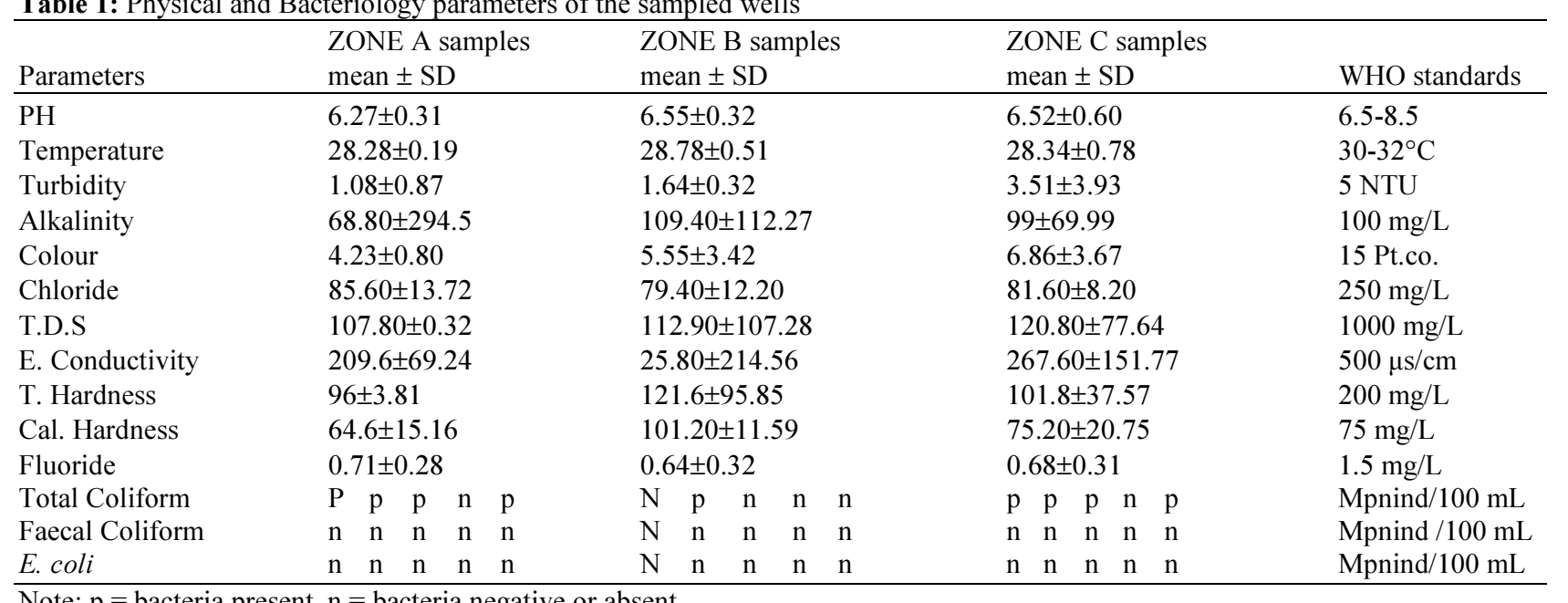

Note: $\mathrm{p}=$ bacteria present, $\mathrm{n}=$ bacteria negative or absent 
This again confirmed the slightly acidic nature of water of the study zones. Hence, water from these commercial wells requires some level of treatment to attain the required WHO standard. The World Health Organization (WHO, 1998) International Standard for Drinking Water classified water with a total hardness of $\mathrm{CaCO}_{3}$ less than $50 \mathrm{mg} \mathrm{L}^{-1}$ as soft water, 50 to $150 \mathrm{mg} \mathrm{L}^{-1}$ as moderately hard Water and water hardness above $150 \mathrm{mg} \mathrm{L}^{-1}$ as hard $\mathrm{CaCO}_{3}$. Based on these classifications, all the water samples analyzed were moderately hard water, thus the ground water is suitable for domestic use in terms of hardness. This is because moderately hard water is preferred to soft water for drinking purposes as hard water is associated with low death rate from heart diseases (ISO, 1990). $\mathrm{Ca}^{2+}$ and $\mathrm{Mg}^{2+}$ values obtained for the water samples ranged from 15.2 to $40.0 \mathrm{mg} \mathrm{L}{ }^{-1} \cdot \mathrm{Ca}^{2+}$ and $\mathrm{Mg}^{2+}$ are among the general elements essential for human health and metabolism and should be available in normal drinking water. However, the indication of one or more of these elements occurring in the water above certain limits, the water may become objectionable to consumers and even become hazardous to health.

\section{Conclusion}

The sampled wells from all the three Zones selected showed that on the average, the ground water within the municipality were all slightly acidic. The levels ofpH in the groundwater should be monitored regularly to keep them from acidifying the water. The Electrical Conductivity of all the sampled wells were within the WHO standard. However, the levels of EC recorded were relatively high for groundwater; which might not be very suitable for domestic and agricultural use because of their high salinity levels. Generally, all the physicochemical parameters of the groundwater were all within the WHO recommended values, however, Bacteriological analysis revealed that Total Coliform values of all the sampled wells indicated positive $(+++)$ for bacteria present. This showed most the sampled wells were positive to Total coliform test an indication that water should therefore be treated before consumption.

\section{Acknowlwdgement}

Appeciation to the stafff and Technicians at the Water Quality Laboratory of the Ghana Water Company Ltd (GWCL) and officers of Environmental Protection Agency (EPA) in Sunyani,Ghana.

\section{Authors Contributions}

Kwabena Antwi Kusi: Conducted the experiment.

Samuel Wiafe: Analysed the field data in the laboratory.
Patrick Akaribila Nsonini: Assisted in the experiment and laboratory analysis.

\section{Ethics}

To the best of our knowledge this research was conducted without any ethical violations.

\section{References}

Ackah, M., A.K. Anim, E.T. Gyamfi, J. Acquah and E.S. Nyarko et al., 2012. Assessment of the quality of sachet water consumed in urban townships of Ghana using physico-chemical indicators: A preliminary study. Adv. Applied Sci. Res., 3: 2120-2127.

Amaniampong, S.B., 2015. Developing an option for sustainable plastic waste management in Ghana: A case study of sunyani municipality, Ghana.

Anthony, B. and S. Sylvester, 2013. Investigation into the quality standard of sachet water. Takoradi Polytechnic.

APHA, 1992. Standard methods for the examination of water and wastewater. 18th Edn., American Public Health Association.

Asiedu, A.B., 2012. Household access to water and sanitation facilities: A case study of the Offinso South Municipality.

Buamah, R., B. Petrusevski and J.C. Schippers, 2008. Adsorptive removal of manganese (II) from the aqueous phase using iron oxide coated sand. J. Water Supply: Res. Technol., 57: 1-11.

DOI: 10.2166/aqua.2008.078

Danquah, E. and J. Agyei-Ohemeng, 2015. Impact of Eidolon helvum on roost trees on UENR campus. JENRM, 2: 44-50. DOI: 10.26796/jenrm.v2i0.43

GSS,2000. Population and housing census, summary report of final results, Ghana Statistical Service, Accra.

ISO, 1990. Water quality determination of sum of Calcium and Magnesium. EDTA titrimetric method. (ISO, 5815); International Organization for Standardization, Geneva.

Obeng, M., 2015. Assessment of groundwater quality in Bogoso, a mining community in the Western region of Ghana.

Okoye, C.O. and A.C. Okoye, 2008. Urban domestic solid waste management. Nimo: Rex Charles and Patrick Limited Awka.

Osumanu, K.I., L. Abdul-Rahim, J. Songsore, F.R. Braimah and M. Mulenga, 2010. Urban water and sanitation in Ghana: How local action is making a difference.

Pote, J., L. Haller, R. Kottelat, V. Sastre and P. Arpagaus et al., 2009. Persistence and growth of feacal culturable bacterial indicators in water column and sediments of vidy bay, Lake Geneva, Switzerland. J. Environ. Sci. China, 21: 62-69. PMID: 19402401 
Rao, K.Y., M.S. Anjum, P.P. Reddy, M. Monica and I.A. Hameed et al., 2016. Physico-chemical and bacterial evaluation of public and packaged drinking water in Vikarabad, Telangana, India-Potential Public Health Implications.

SMA, 2010. Municipal action plan report. Sunyani Municipal Assembly, Sunyani.

SMA, 2014. Draft 4-year medium term development plan (2014-2017). Sunyani Municipal Assembly, Sunyani.

SMA, 2018. Sunyani Municipal Assembly.

UNCT-GH-MDG7, 2018. UNCT-GH-MDG7Environmental-Sustainability.

UNICEF, 2008. UNICEF Handbook on Water Quality. 1st Edn., United Nations Children's Fund (UNICEF), New York, pp: 179.
Utsumi, H. and Y. Tsuchiya, 2010. Water quality and standards.

WHO, 1998. Guideline for drinking water quality: Health Criteria and other supporting information. 3rd Edn., World Health Organization, Geneva

WHO, 2006. Guidelines for drinking-water quality [electronic resource]: Incorporating first addendum. Recommendations, World Health Organization.

$\mathrm{Xu}, \mathrm{Y}$. and B. Usher, 2006. Groundwater pollution in Africa. Taylor and Francis, London.

Yilmaz, E. and C. Koc, 2014. Physically and chemically evaluation for the water quality criteria in a farm on Akcay. J. Water Resour. Prot., 6: 63-67. DOI: $10.4236 /$ jwarp.2014.62010 